\title{
Los hermanos Machado y el Norte de Africa
}

(Notas sobre un aspecto poco estudiado de las colaboraciones de Manuel y Antonio Machado en La Caricatura en 1893)

Juan Alfredo Bellón Cazabán

Universidad de Granada

El 15 de octubre de 1893 ve la luz en Madrid un número más del semanario satírico La Caricatura y en él los lectores pueden divertirse con una especie de crónica miscelánea titulada "La Semana", firmada con el seudónimo de "Tablante de Ricamonte". Las entradillas son: MOROS EN LA COSTA.- LO QUE SE DICE.- LO QUE SE ROBA.- ECHANDO CHISPAS (1). El texto comienza así:

¿Pero cuándo les vamos a dar ese puntapié a los moritos de Africa, que no hacen otra cosa que molestarnos continuamente, sin vergüenza ni miramientos de ninguna clase?

¿De qué nos sirvió la tremebunda paliza con que les regalamos, aún no hace muchos años, si para que estemos seguros en aquel territorio nuestro por todos conceptos, no nos vale de nada? 
¿Para qué mantener alli peligros $y$ desasosiegos que hemos podido evitar con una miajita de energía? ¿Y para qué derrochar la sangre y la vida de nuestros soldados, empeñada en una lucha de escaramuzas en la que nada hemos de ganar, porque la paz oficial nos veda toda represalia? (2).

La Caricatura era una publicación periódica semanal resucitada por un editor catalán afincado en Madrid y reconvertida, para esta su segunda época, de revista frívola de carácter gráfico en revista satírico-literaria de altos vuelos (3). Dirigía la publicación Enrique Paradas (4), poeta gaditano de veta popular, y la ilustraba Angel Gutiérrez Pons (5). La redacción permanente estaba integrada por el mencionado director y dos jóvenes meritorios de diecinueve y dieciocho años respectivamente: Manuel y Antonio Machado quienes unas veces eran "Polilla" (Manuel), otras. "Cabellera" (Antonio); a veces, ellos mismos (Manuel) y, cuando no, "Tablante de Ricamonte". Como el propio Manuel dijo, trabajaron durante casi cerca de un año para la revista "gratis et amore" haciendo así sus primeros pinitos periodísticos y literarios.

No es este el lugar para estudiar en profundidad las revistas satíricas de finales del XIX, pero sí para enmarcar en ellas el texto arriba transcrito: se trataba de publicaciones más o menos chabacanas que basaban la mayor parte de su éxito en las referencias de coyuntura y en la crítica política y costumbrista principalmente. Algunas, como La Caricatura en su segunda época, adobaron lo que les era originariamerlte consustancial con colaboraciones literarias de alto copete (6), pero, en última instancia, su razón de ser y de ser leídas estribó siempre en lo satírico.

Sólo teniendo en cuenta lo anterior, puede entenderse el tono frívolo del texto arriba transcrito y sólo así se comprende lo que, párrafos después, acaba por convertirse en un chiste, basado en un aparentemente ingenuo juego de palabras:

-Vamos a Melilla a vengar un sangriento ultraje- decía la otra noche en el café un coronel retirado a un maestro de escuela que se estaba tragando de un bocado la media tostada que le había servido un camarero. 
- ¿A qué? ¿a que nos coman vivos?- replicó este último. ¿Quiere usted que después de carecer tantos años de alimento, ofrezcamos en crudo, usted su carne y yo mis huesos a apetitos tan feroces.

Si en vez de tratarse de moriscos se tratase de mariscos, yo le aseguro a usted que iría a destrozarlos con ensañamiento.

Pero ir a Melilla a batirse... que vaya Mella (7).

Lo curioso del caso es que la tragedia de vidas humanas en el campo de Melilla comenzó en tono de sainete aunque acabara en tragedia: en octubre del año 93 se produjo un incidente fronterizo en la franja de terreno que separaba Melilla del territorio marroquí donde fue levemente herido un soldado español cuando se construía una línea de fortines, uno de ellos próximo a un cementerio musulmán. Las protestas de los rifeños no dieron resultado y se produjo una revuelta por efecto de la cual quedó destruido el fortín. Al reanudarse el trabajo bajo la protección del ejército, tuvo lugar un enfrentemiento armado en el que perdieron la vida el general Margallo y "diecinueve valientes" más.

En España (la España donde ya estaban madurando las condiciones que darían lugar al desastre colonial de 1898) la noticia causó gran impresión y el Ministro de la Guerra, López Domínguez, decretó la movilización e improvisó una expedición de 22.000 hombres, mal equipados y con peor moral, al mando del general Martínez Campos. La movilidad de la impedimenta militar estaba asegurada por 600 acémilas.

El sultán de Marruecos, Muley Hassan, no había declarado la guerra y, en cierto modo, se desentendía de las actividades bélicas de los rifeños. Los reveses fueron múltiples debido a la atipicidad del enfrentamiento, a las acciones de guerrilla de los marroquíes y a la incapacidad del ejército-español, formado entonces en su totalidad por 243 generales, 229 jefes de Estado Mayor, 16.962 oficiales y 98.446 soldados (8).

El incidente de Melilla demostró que España no estaba preparada para llevar a cabo empresas coloniales de carácter bélico en el norte de Africa, lo que sólo la hacía acreedora en el concierto de las potencias europeas a ocupar un status de potencia secundaria a la hora del reparto colonial. 
A esto debe sumarse la incapacidad para controlar la insurgencia dentro de sus propias colonias de ultramar como quedaría demostrado en el 98. y para solucionar los graves problemas de la metrópoli.

En efecto, la crisis económica internacional de 1890-92 afectó gravemente a la nada pujante situación española y contribuyó sobre todo a la depresión del sector industrial y, especialmente, del minero, hasta tal punto, que los conservadores - antes de dejar paso al bienio liberal en que nos encontramos (el de los "buenos administradores / de su casa") - tuvieron que implantar un arancel proteccionista y ceder a las exigencias de la burguesía catalana para preservar la competitividad de sus productos en el mercado interior.

Recuérdese también que el sufragio universal acababa de ser aprobado en 1890-91 aunque sólo para los varones mayores de venticinco años. Este relativo "balón de oxígeno" democrático sirvió para bien poco, desvirtuado como estaba por la política bipartidista y por los resabios caciquiles. En realidad, puede decirse que el sistema canovista estaba entrando en crisis por no haber sido capaz de generar las ideas ni las fuerzas que propiciaran una auténtica "regeneración" de la vida pública española. Todo este panorama era terreno abonado para que surgieran la crítica y el desencanto rupturistas y se levantaran voces de los sectores intelectuales más avanzados, relacionados con la burguesía más innovadora y entroncados con los residuos republicanos y con los movimientos emergentes del anarquismo y del socialismo (9). Cajas de resonancia de estas tendencias fueron también los movimientos renovadores de carácter pedagógico entre los que destacó la Institución Libre de Enseñanza donde no por casualidad se habían educado los hermanos Machado.

Hasta aquí el cuadro histórico y cultural. Pasemos ahora a centrarnos en la figura de los dos hermanos y en el sentido de estas sus primeras producciones en colaboración. Parece que hay acuerdo entre los especialistas en la imposibilidad de discernir lo que a cada uno se debe en las obras firmadas por ambos (10). El seudónimo "Tablante de Ricamonte". aparte de evocar a algún personaje propio de los libros de caballería, parece sugerir el proceso de ósmosis creadora como modo de trabajo fundamental en las publicaciones firmadas en colaboración. De hecho, estas crónicas semanales de La Caricatura parecen relatos de mentidero de la vida madrileña y se refieren a sucesos conocidos o vividos por Manuel y Antonio 
"a la alimón". Otra cosa sería saber si alguno de ellos se encargaba especialmente del verso o de la prosa, si los juegos de palabras y otros procedimientos estilísticos satírico-burlescos se debían al ingenio especial de este o aquel o si los comentarios jacobinos más zahirientes venían de uno u otro caletre.

En efecto, resulta aventurado intentar una adscripción ideológica de algún fragmento, cuando parece que la formación familiar y escolar y aún el talante de crítica hacia el entorno cuadraban a ambos por igual en esta década de los noventa. No me resisto, sin embargo, a señalar en el caso de Antonio algunos elementos que anticipan desarrollos futuros de su obra:

a) De una parte, el tema de las conversaciones o charlas de café y tertulia — también de rebotica一, con diálogos incluidos, que con tanta originalidad consiguió plasmar luego en sus famosas Meditaciones Rurales.

b) De otra, el tono sentencioso de una prosa que incluye en su interior el diálogo dramático, generalmente entre dos personas, la primera de las cuales plantea una tesis más o menos extendida entre el público (- Vamos a Melilla a vengar el sangriento ultraje) y la segunda, la antítesis escéptica y guasona ( $-¿^{A}$ qué, a que nos coman vivos?). Dialéctica esta muy del gusto de Antonio desde la primen entrega de Juan de Mairena: "- La verdad es la verdad, dígala Agamenón o su porquero..." etc. Humor dialéctico y zumbón lleno de escepticismo.

Basta con repasar las cinco entregas de La Semana en las que aparece alguna referencia al conflicto norteafricano (11), para comprobar que el tema de Melilla no es más que un pretexto de coyuntura para trascender la anécdota y pasar a afirmar en tono crítico bastante más ácido de lo que hasta ahora se había pensado, la impotencia nacional y la inoperancia de los gobernantes para solucionarla.

Señalaré, en apoyo de esta tesis, varios pasajes de La Semana donde "Tablante de Ricamonte" parece anticiparse al futuro desenvolvimiento ideológico de Antonio bastante más que al de Manuel, aunque reconozco de antemano que en 1893 ambos podían estar absolutamente identificados al respecto.

Así, en la página 1.130 de las Obras Completas (edición de Oreste Macrí citada en nota 1) se exige "acabar de una vez con estas hostilidades tan infructuosas como sangrientas." Más adelante se afirma que "el pequeño altercado de Melilla no pasa de ser un pequeño tumulto de los mil 
con que nos obsequian [nuestros gobernantes]". Luego se llega a decir que "dentro de nuestro propio domicilio tenemos hordas salvajes que nos hacen más daño que los moros... Pues ja limpiar la casa de vándalos y después barrer a los de Melilla, pero antes a los que tenemos en la costa y que tanto nos cuestan!" (12). Pero no para ahí la crítica a la gravedad de la situación nacional: tras quejarse amargamente de las condiciones en que llegaban al norte de Africa las tropas.

$$
\begin{aligned}
& \text { mal comidos, peor armados } \\
& y \text { dispuestos a sufrir } \\
& \text { la peor desaladera } \\
& \text { de aquellas bestias del Rif (13). }
\end{aligned}
$$

"Tablante" vuelve a trascender la anécdota de lo lejano y pone en boca de un funcionario de Correos. que desea marchar de voluntario, una crítica mucho mas ácida:

Parece lógico pensar que la información de que disponían los jóvenes escritores era la que le suministraban periódicos y mentideros de tertulia y que sus crónicas semanales no hacían sino sacarle punta a lo consabido por los lectores de La Caricatura. Esto lo conseguían en dos direcciones, la de la sátira política a la impotencia gubernamental y la del chiste intrascendente y a veces ingenuo, basado en la consideración exótica de lo norteafricano. Y digo exótica por distanciada, tanto como pudicra serlo el tema de ultramar en los aventureros del XVIII o en los viajeros románticos del XIX. Véase si no. ahora sí, la naïcelé de estos comentarios:

\author{
Que está muy bien que el Sultán \\ se rodee de placeres... \\ Sí, pero por muy barbián \\ que sea Muley Hassán, \\ son mucho seis mil mujeres (15)
}


Los jóvenes Machado se permiten a continuación hacer un chiste al respecto, no sin cierta gracia eufemística. Una vez más se trata de un procedimiento estilístico socarrón que parece anticipar el futuro desenvolvimiento del humor en la obra de Antonio:

I, a propósito, sería curioso saber lo que piensan de lodo esto las seis mil chicas de Muley Hassán. Tendrá que verse la serie de cosas que dirán de nosotros aquellas barbianas. Yo iría con gusto a Tánger por echar con cllas un parrafito (16) y oirles su opinión sobre los sucesos de Melilla (17).

Otro aspecto que me parece interesante subrayar es la tendencia estilística a la coloquialidad que se observa en todos estos textos. Cireo que ello es asimismo otra de las características de una buena parte de la obra de Antonio. En este caso, cuando hablo de coloquialidad me refiero a la frecuencia con que usan giros idiomáticos de lodos consabidos para caracterizar una situación. Torlo el mundo conoce la frase "una cosa es predicar y otra dar trigo". Pues bien. "Tablante" explota este y otros clichés tradicionales en un pasaje donde se critica de nuevo la mala marcha de la cosa pública:

El jno lo entiende usted!, este grito lan espontáneo y tan expresivo que se dice en muestras plazas de toros a los malos presidentes, se te ha repetido a muestros actuales hombres de Estado, que las gargantas están ya roncas de lanto esforzar la voz para emitirlo.

Hay que desengañarse "que una cosas [sic] es predicar y otra dar Irigo". Quiero decir que una cosa es promunciar discursos y otra llevar su contenido a la práctica. Una cosa es que Sagasta en la oposición resulte un hombre hábil, con su miajita de intención y sus adarmes de oportunidad, $y$ otra que en el poder no se sepa lo que se pesca (18).

La frecuencia de estos artilugios estilísticos en la crítica periodística relacionada con el humor puede sorprendentemente encontrarse con referencias casi similares en un reciente artículo de Joaquín Vidal aparecido 
en la última página de El País el 28 de mayo de 1991, a propósito de las elecciones municipales y autonómicas del día 26 del mismo mes. Su título es "Dar trigo" y su párrafo final dice así: "pero ya tienen los votos. Y ya mandan donde querían mandar. Y si, además, dieran sólo la mitad del trigo que han prometido, esto sería jauja" (19).

Traigo a colación esta última referencia porque pienso que la crítica periodística, en su modalidad humorística y satírica, es una de las costantes más significativas en la historia de la literatura española en los cien últimos años. Los Machado, desde este semanario decimonónico estaban avanzando hacia la posterior transformación del humor periodístico español: el de La Codorniz, Hermano Lobo y Por Favor; para no citar más que tres de los hitos más recientes de la literatura satírica del siglo $\mathrm{XX}$. Bien es verdad que el humor de La Caricatura dista mucho del de las citadas publicaciones. Aurora de Albornoz habla al respecto de

un tono satírico siempre, bastante cercano a la inocente sátira -así diría Manuel años más tarde-que domina muchas de las publicaciones del momento; El Madrid Cómico muy destacadamente (20).

También es cierto, como piensa la misma autora, que si ambos hermanos no hubieran escrito nada después de estas colaboraciones en $L a$ Caricatura, nadie concedería el menor interés ni a ellos ni a su obra. Leyendo estas páginas tenemos la impresión de estar buceando por las raíces interiores del conjunto de sus producciones literarias y, por tanto, ideológicas. $A$ mí se me antoja además que esto se ve más claro en el caso de Antonio que en el de Manuel. Parece que se tiene la sensación de entender cómo y por qué escribían entonces lo que escribían.

De esta forma, podrían sacarse algunas conclusiones tras la atenta lectura de los cinco artículos firmados por "Tablante de Ricamonte" en los que se hace referencia al conflicto de Melilla.

En lo que atañe a la forma literaria, la estrecha colaboración entre ambos hermanos no hace fácil adivinar qué parte o aspecto pudiera deberse más a Manuel o a Antonio. Sin embargo, quizá pueda apuntarse. con las debidas reservas, que existen elementos que luego se desarrollarán. 
especialmente en la obra del segundo, como el gusto por los giros idiomáticos coloquiales y el uso frecuente de diálogos ficticios, sosteniendo posturas encontradas, para ofrecer al lector una visión dialéctica y escéptica de los temas tratados.

En lo referente al conflicto norteafricano debe entenderse que los casi adolescentes periodistas lo trataron por ser noticia de enorme interés social y político en el otoño de 1893 más que porque a ellos les preocupara prioritariamente.

Lo que ocurre es que le dieron un tratamiento propio de los círculos intelectuales y progresistas de la época, usando el humor para oponerse a las aventuras neocoloniales de fines del XIX: si ya costaba Dios y ayuda mantener los restos del imperio ultramarino, no era cosa de embarcarse en empresas transmediterráneas. Y mucho menos que eso, tampoco era cosa de usar los sucesos de Melilla como cortina de humo para ocultar la gravedad de la situación en la metrópoli, donde estaba empezando a ser patente la grave crisis del sistema canovista y, por tanto, de la Restauración.

Los jóvenes intelectuales españoles que, como los Machado, se habían educado en el manejo instrumental de la crítica y en los ideales de la Institución Libre de Enseñanza, usaron la prensa humorística para zaherir a un sistema social, económico y cultural que ya no les era aceptable. Cualquier pretexto resultaba válido para trascender del análisis de lo concreto y formularse como una manifestación de rebeldía contra lo establecido. Ese pretexto fue en este caso lo africano, como también lo fueron las anécdotas de la explosión de un barco en Santander o las revueltas antigubernamentales del País Vasco:

... Porque es lo que dirá Sagasta.

- Desde que estamos en el poder, España entera ha sido un campo de batalla. En Vitoria nos han saludado a pedradas, con algún batacazo por añadidura; en San Sebaslián, a ladrillazos; en Bilbao, a tiros; no ha habido un solo día que la prensa haya dejado de relatar tres o cuatro motines y; por consiguiente, el pequeño altercado de Melilla no pasa de ser un pequeño tumulto de los mil que nos obsequian (21). 
Si a todo esto se añade el surgimiento de los nacionalismos burgueses vasco y catalán, que es precisamente lo que estaba ocurriendo por las mismas fechas, puede afirmarse que la crisis del sistema estaba servida: sólo faltaba la gota de agua de los desastres de 1898.

Otro aspecto que aparece entre líneas en estas colaboraciones juveniles de los hermanos Machado es la preocupación por la vida de los "soldaditos" españoles que tenían que acudir a apagar tantos pequeños y grandes fuegos, estos de los residuos imperiales; aquellos de los escarceos neoimperialistas;

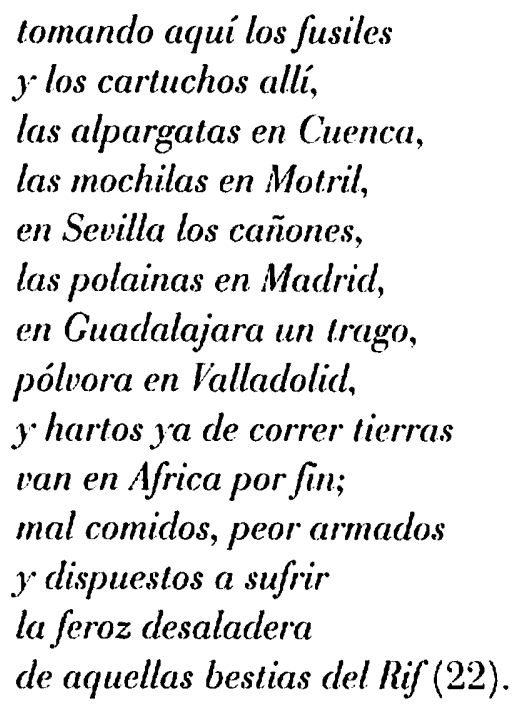

Recuérdese que por entonces ya existía el sistema de "cuota" y que eran los jóvenes campesinos y los de las clases urbanas más desfavorecidas quienes no podían eludir la llamada a filas y, mucho menos, las movilizaciones. La crítica progresista de los hermanos Machado supo captar la injusticia de esta situación y escarneció la instrumentalización política que se hacía desde las clases acomodadas y desde el poder de aquellas vidas inútilmente ofrendadas a una defensa estúpida del patrioterismo español.

Lo anterior vale por igual para los dibujos con textos humorísticos de Angel Gutiérrez Pons entre los que pueden lcerse cosas como las siguientes: 
Bueno, que castiguen a los moros ipero que no tiren balas que me van a estropear el paisaje! (Un explorador con salacol $y$ bastón) (23).

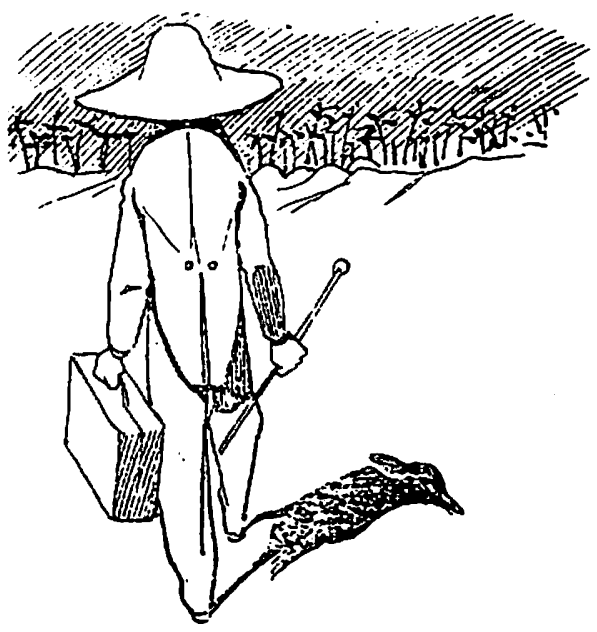

¡Si los moros pagaran bien las tablitas!...

Si yo fuera general, lo primero que hacía era matar a todos los moros; jy ya tenía usted la guerra acabada! ¿Ve usted? Si es que aqui no lo entienden.

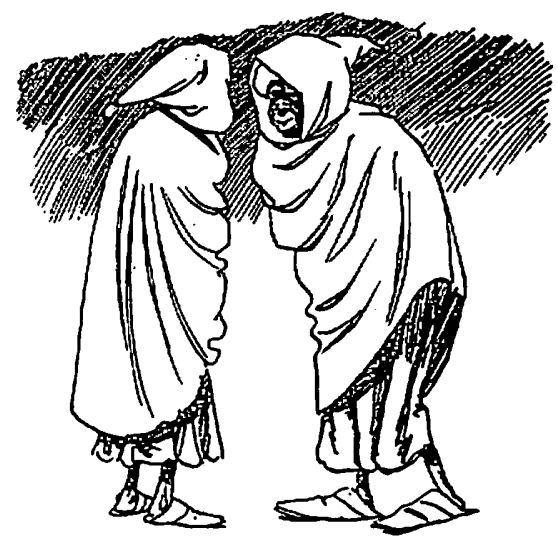

(dos moros con chilaba:) -¿Has visto qué brutos son los españoles?

- ¿Pues no nos quieren pegar! 
(una dama): En Marruecos también habrá chicos alojados que dispongan de una fortuna.

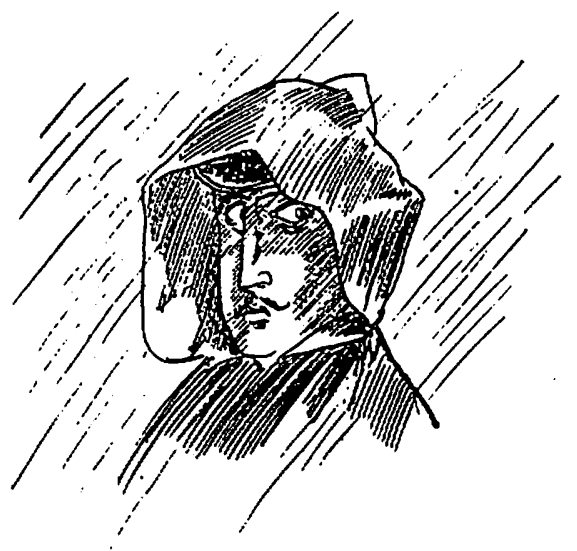

(caballero con la cabeza cubierta por la capucha de un impermeable): ¡Me miran! ¿me habrán tomado por un moro?

(otra dama con traje de montar y fusta): Si a nosotras nos dejaran ir a Africa, creo que conseguiriamos de los moros más que los soldados.

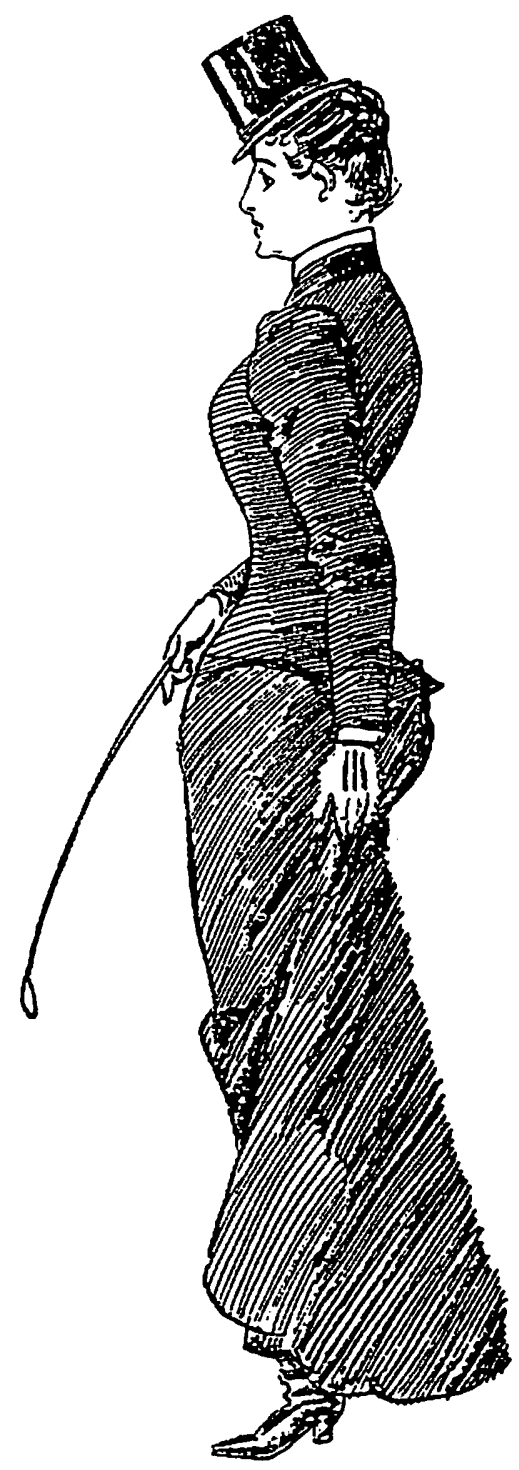


[dos burgueses adinerados:] Vo siento más que nadie las bajas de nuestro ejércilo, porque como presto a militares y empleados...

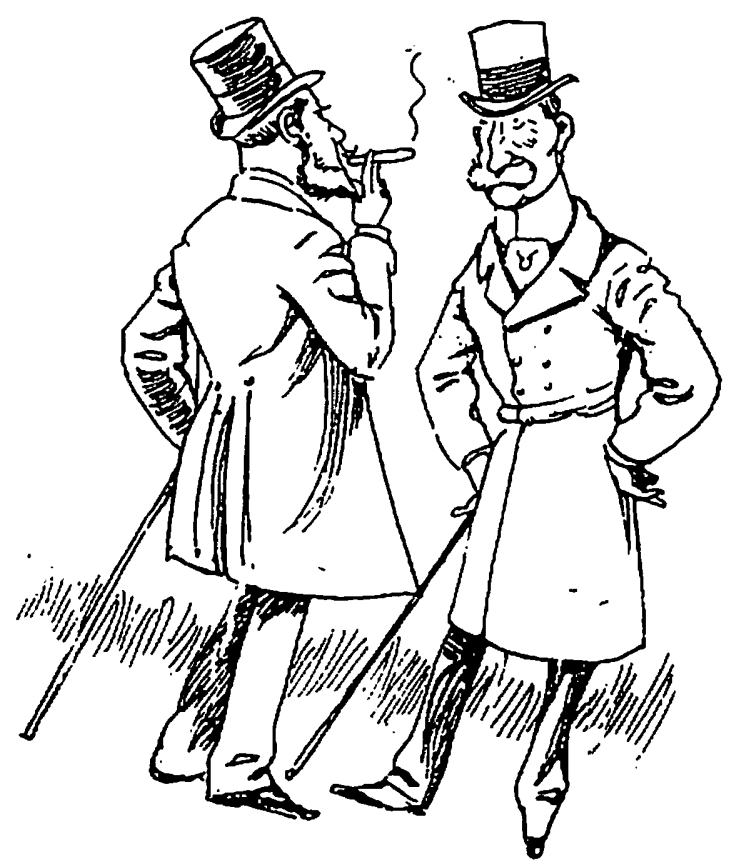

La dureza y corrosividad de estos textos a pie de ilustración y su indudable conexión con el talante que hemos observado en los de La Semana, pueden ser entendidos de cualquier forma menos como "inocente sátira" aunque sea esto último lo que piensan Yiguel Pérez Ferrero y Aurora de Albornoz citando palabras textuales de Manuel Machado. Son sátiras mucho más que zahirientes, invectivas contra las hipocresías sociales y contra la instrumentalización del dolor, de las penalidades y de la muerte de tantos seres humanos en guerras inútiles (24).

Quiero terminar recordando que la preocupación prioritaria de los Machado en La Caricatura no fue la cuestión de las escaramuzas neocoloniales en el norte de Africa. ni el conocimiento profundo de las situaciones que allí se daban, ni el de su historia, ni el de sus perpectivas de solución. La opinión pública española y los círculos intelectuales progresistas de hoy conocen el problema con más profundidad y lo afrontan seguramente con mayor madurez y seriedad que los de hace un siglo. 
Pero la historia es cíclicamente caprichosa y repite tozuda con nuevos ropajes epifenoménicos cuestiones que, como se convendrá, nada tienen de nuevas. En este sentido, sería muy curioso y seguramente aleccionador comparar las reacciones de los intelectuales en los medios de comunicación a propósito de "LO DE MELILLA" con las que recientemente se han producido entre nosotros con motivo de la participación española en la Guerra del Golfo Pérsico, y luego comprobar: por las características de las mismas, la matriz ideológica y política de escritores, comentaristas, periódicos y emisoras de radio y televisión en las que aparecían. Porque la guerra y el humor no son cosas tan diferentes: el humor y la sátira son muchas veces la prolongación de la guerra por otros medios. 
1. Para facilitar el acceso ul material cimalo, refiero los textos de La Caricatura a la edición a cargo de Oreste Macri de las Prosas Complefas de Amonio Machado. Madrid. Fipasa Calpe. 1988. págs. 1.129 y ss. En adelante vilaré A. Machado. op). cil., etc.

En lo reference a estudios solore ambos lacemanos. he mancjado además: Miguel Pérez Ferrero. Vida de Antomio Machado Y. Mannel. Madrid. lispasa Calpe. Colección Austral. $1973\left(3^{4}\right.$ ed.) y Bernard Sesé. Amlorrios Machado (1575-19.36) it Ilombre. El Poefa. El Pensador: Madril. Credus. 1980 (2 vols.).

El mareo histórico de referemeia esta hasaldo rn la conocisla Ilistoria de Espaina dirigida por $\mathrm{V}$. Tiunón de Lara, A $\mathrm{VV}$.: t. VIII, Barcelona, Ed. lahor. 1981. y en el lihro do Julio Buscjuets Militar de Carrera en España. Barestoma. Eil. Ariel. 1975 (2" ed.).

Quiero agradecer también. en lo que respecela a este último npar1ado. las indicaciones de mi colega, el prolesor Amtonio Cirl liméne\% con yuien he charlado en varias ocasiones sobre la situación espanola y norteafricana en la dicada 1890-1900

2. A. Machado, op. cil., págs. 1.129-1.130.

Vótense aupui los dos subrayados con intrución humoristica. Nuestro critica obviamente el carricter tautológico de la mayoría de las argumentaciones sobre la españolidad de las plazas africanas. Como veremos en la uiltima págima de este 1rabajo, esios recursos a la iromía som típicos de la izquierda española desde el XIX hasta mustros días. El caso de miajiza tiene otra explica. ción. Aparecer con frecuencia en La Semona y siempre referirlo a Sagasta. lo que me hace pensar que lo tenía vomo muletilla. Además, la gralia es una aproximación a la promunciación andaluza de migajiza con pérdida de la " $\mathrm{l}^{*}$ intervocálica.

3. Debo agradecer una primera y decisiva impresión de estos datos a mi colega el profisor Migued D'Ors I.ois, que amable y desinteresalamente ha puesto a mi disposición un trabajo que tiene ya en la imprenta sobre La Proto-llis/oria Poética de ،. Machado. El profe:sor D'Ors me ha proporcionarlo cumbién las fororopiats de La Caricaturu prumeventes de las (jue existen en la l lemeroteca Vacional y me la ayudalo así mismo con III amplio cambio de impresiones sobre el incrés que puede tener esta comumicación para aclarar aspectos de la obra juvenil de Antonio y Mamuel
Machado ciertamente conocidos pero poco estudiados hasta el momento.

4. (ifr. Aurora de Albornoz. La Prohistoria de .1. 1\%. E.l. Ia Torre. Liniversidad de Puerto Rico. 1961 y también "(Cabellera o "Pre-Anco-

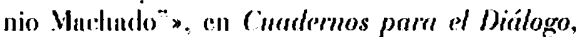
XIIX Fxtraordinario. nov.. 1975. págs. 28-31. En este articulo se dice que "Esos primeros articulos - muy anteriores por supuesio a los primeros peremas de que tenemos noticia- se publicaron en la Caricalurn, un periodiquilla que hacía Enripue Paradas, poeta olvidado hoy y mu estimaclo siempire por Antenio".

5. Aunque la lirma de la ilustraciones gráficas cra 1 . Pons, el nombre completo em Angel Guliérre\% Pons. Como veremos más adelante. este humorisia gráfico publicó en La Caricalura gran cantidal de dibujos con referencias satiricas - a veces despiadadas- al conflicto norteafricano que tanto se estaba desorhitando en la Península. La prictica totalidad de esos "chistes" aparecen intercalados contre artículos, poemas y colaboraciones que no ticnen absolutamente mala que ver con el tema. En realidad son la carce grafica de los comenturios satiricos que -Tablante de Ricamonte" escribia en la sección -La Semama".

6. Miguel D'Ors, op. cil.: "Nucstro buen hombre consiguió también algunas colahoraciones ilustres para la revista: Campoamor. Eduardo Benos. Fimilio Ferrari. Salvador Rueda. Manuel Reina. (16:.

7. 1. Machado, op. cil., pág. 1.131.

Vo es esta la ímien vez en que "lablame" usa la paronomasia para fundar el juego aparentemente ingenuo de su humor. Más adelente (pág. $1.13+$ ) escribe: ¡Pues a limpiar la casa de vándalos y después barrer a los de Melilla, pero ames a los que lenemos en la cosia y que tamo nos cueslan!". (lil subravado es mio). Oro houón de muestra: en la página 1.1:31 puede lecrse: - Ia gente está cavila que cavila buscando un medio para rastigar a las Kálbilas rifeñas”.

8. Cfr. Manuel 'Tuî́n de Lara y Julio Busquets en las obras cilaclas en la nota 1.

9. Conviene recordar que Fermin Salvochea asistía a veres a la certulia de don Eduardo Benot de la cuur cran asiduos Antomio y Manuel Machado.

10. Aurora de Alhornoz., en el arliculo citado en la nota t. eseribe al respecto: "Todo investigador yue ha estudiado la obra teatral de los Nachado -escrita. como se sabe. en colaboración y ell la madurez literaria de ambos- ha encon- 
Irado grandes dificultules al pretender determinar dónde empieza el uno o termina el otro. Eintre lo poco que sobre este punto conocemos con certeza. se sabe. por ejemplo, que alguno de los fragmentos de La Lola se va a los puertos, que recuerdan algunos versos de Manucl, son, sin embargo, obra de Antonio. Si esto surede en el momento en que los dos hermanos tienen una definida personalidad. zcómo intentar determinar hasta dónde llega la colahoración del casi aulolescente Antonio en los artículos firmulos por "Tahlante de Ricamonee? Ello es, por supuesto. absolutamente imposilste".

11. Los articulos de La Semana solín aparacer en la primera página de La Caricatura y los que hublan de la crisis melillense son los cinco que aparecen entre el 15 ale octubre y el 22 de noviemlve de 1893.

12. liste recurso a la paronomasia ya se ha señalado y comentado en la nota ?.

13. Antonio Machado, op. cil., pig. 1.138.

Poco favor parece hacerles "ithblante" con este y otros calificativos a los norteafricnmos. Pienso, sin embargo. que aquellos "salvajes" que "comían carne humana" no son sino el pretexto, como vengo diciendo, de la sátira matharliana hacin las expresiones de la época. El propin profesor D'Ors. a quien ya he agradecido sus informaciones en la nota 3. me decia recordar que en casa de sus abuelos. cuando los nietos se deshordalan con las travesuras propias de la edad, eran frecuentemente admonidos con frases de esta guisa: "ilistáis hechus unos rifenos!". Villos, desde luego, sólo entendíu la palabra en el semtido de "salvajes".

Véase también al respecto este otro poemilla "caritativo" en A. Machado, op. cit., prig. 1.138:

Con los morilos aquellos

mo hav que andarse con tibieza

sino duro, yentereza,

que les sobma a torlos ellos

la cabeza.
Y, para terminar, véase este otro fragmen10 de "Tahlaune". pág. 1.147: "Y ahí tienen usiedes lo que son las cosas. lil barco cargado de dinamita que estalló en Santander. hubiera sido un medio de exterminar a los rifeños de Ariea, siempre fue nosotros nos hubiéramos podido salvar. Y hubiera sido un medio. por to salvaje. digno de emplearlo en ayuella tierra del Riff".

14. Ile ayui un ejemplo evidente de lo cue vengo sostenientlo sobre el uso de la anéchlota norleafricana como mero pretexio pero criticar la situación de la metrópoli. A. Machado. op. cit. paig. 1.1+2.

15. A. Machardo. op. cit. pán. 1.138.

16. El eufemismo "echar uni parrafito" parece remitir a los chistes más tópicos de los espectáculos arrevistudos.

17. A. Machado. op. cit. pág. 1.13?.

18. A. Machatolo. op. cit., prig. $1.1+1$.

19. Fl Pais, 28 de mavo de 1991.

20. Cfr. Aurora de Albormo\%. artículo citadı ell nota 4.

21. A. Muchuclo, op. cil. págs. 1.133-1.13ł.

22. A. Machado, op. cil., paig. 1.1ti.

23. A. Machado, op. cil., píg. 1.1+1: "Ila lubbido, sí, desgraciedamente, unos cuantos heroes que han dado la vida por su patria: unn prueba de la inutilidad. ineptitud y cobardía de mestro lisiado Gobierno. y una ocasión en la yoe muestro pueblo ha demostrado que duerme. duerme profunclamente, y que si alguna vez despierra es... juy!, para volverse a dormir de muevo.

¡Oh temporu! ¡Oh mores! ¡qué dirán las naciones extranjeras!". 